\title{
Lipoamide protects retinal pigment epithelial cells from oxidative stress and mitochondrial dysfunction
}

\author{
Xuesen Li ${ }^{a, b}$, Zhongbo Liu ${ }^{a, b}$, Cheng Luo ${ }^{a}$, Haiqun Jia ${ }^{a, b}$, Lijuan Sun ${ }^{a}$, Bei Hou ${ }^{a}$, Weili \\ Shen ${ }^{\mathrm{a}}$, Lester Packer $\mathrm{a}, \mathrm{c}$, Carl W. Cotmand, and Jiankang Liu ${ }^{*}$ \\ aInstitute for Nutritional Science, Shanghai Institutes of Biological Sciences, Chinese Academy of Sciences, \\ Shanghai 200031, China \\ bGraduate School of the Chinese Academy of Sciences, Beijing, China \\ cDepartment of Molecular Pharmacology and Pharmaceutical Sciences, School of Pharmacy, University of \\ Southern California, Los Angeles, CA 90089, USA \\ dInstitute for Brain Aging and Dementia, University of California at Irvine, Irvine, CA 92697-4540, USA
}

\section{Abstract}

$\alpha$-Lipoic acid (LA) has been widely studied as an agent for preventing and treating various diseases associated with oxidative disruption of mitochondrial functions. To investigate a related mitochondrial antioxidant, we compared the effects of lipoamide (LM), the neutral amide of LA, with LA for measures of oxidative damage and mitochondrial dysfunction in a human retinal pigment epithelial (RPE) cell line. Acrolein, a major component of cigarette smoke and a product of lipid peroxidation, was used to induce oxidative mitochondrial damage in RPE cells. Overall, using comparable concentrations, LM was more effective than LA at preventing acrolein-induced mitochondrial dysfunction and oxidative stress. Relative to LA, LM improved ATP levels, membrane potentials, and activities of mitochondrial complexes I, II, and V and dehydrogenases that had been decreased by acrolein exposure. LM reduced acrolein-induced oxidant generation, calcium levels, protein oxidation, and DNA damage to a greater degree than LA. And, total antioxidant capacity, glutathione content, glutathione $S$-transferase, and superoxide dismutase activities and expression of nuclear factor-E2-related factor 2 were increased by LM relative to LA. These results suggest that LM is a more potent mitochondrial-protective agent and antioxidant than LA in protecting RPE from oxidative damage.

\section{Keywords}

Mitochondrial complex; Protein oxidation; Oxidative DNA damage; Nuclear factor-E2-related factor 2; Glutathione; Free radicals

\begin{abstract}
Smoking has been identified as a primary risk factor associated with the prevalence and the incidence of neovascular macular degeneration and geographic atrophy [1,2]. Increased exposure to numerous toxins, including aldehydes and NOx, markedly depletes both ascorbic acid levels and protein sulfhydryl concentrations and causes oxidation of lipids and proteins [3-5].
\end{abstract}

Acrolein is one of six aldehydic toxicants present in cigarette smoke. It is an in vivo lipid peroxidation product that has a high hazard index and causes oxidative stress by reacting with 
sulfhydryl groups [6]. Acrolein is about 10-1000 times more toxic than formaldehyde, acetaldehyde, or 4-hydroxynonenal [7] and can reach concentrations of $80 \mu \mathrm{M}$ in the respiratory tract fluid of smokers [8]. In a recent study [9], we treated both human retinal pigment epithelial cell lines (ARPE-19) and primary cultures of human fetal RPE ${ }^{1}$ cells with acrolein and observed similar kinds of oxidative damage and mitochondrial dysfunction, suggesting that smoking may cause oxidative mitochondrial damage that could be a major cause of RPE cell damage. However, $\alpha$-lipoic acid (LA), which is a mitochondrion-targeted antioxidant [10] and mitochondrial nutrient [11], effectively protected RPE cells from acroleininduced toxicity $[9,12]$. These results suggest that treatment with mitochondrion-targeted antioxidants may be an effective strategy for reducing or preventing chronic RPE degeneration induced by oxidants in vivo from a variety of sources, including cigarette smoke.

Lipoamide (LM) is the neutral amide of LA. Unlike LA, LM does not occur naturally in either animals or plants. LM was first synthesized from LA based on the mixed carbonic-carboxylic anhydride method [13]. LM has been shown to be a better cofactor for $\alpha$-oxo-acid dehydrogenase enzymes than free LA, and it is able to promote the recovery of postischemic myocardium in rats $[14,15]$. It also has been shown to be an antioxidant in vitro [16] and prevents Fenton-type chemistry and resultant oxidative damage and apoptosis more efficiently than LA in a lysosomal membrane system [17].

Based on these findings, we hypothesized that LM may be at least as protective as LA against RPE toxicity. In this study, we compared the protective effects of LM and LA in human ARPE-19 cells with acrolein-induced oxidative damage and mitochondrial dysfunction, focusing upon: (1) cell viability and mitochondrial function, (2) oxidant generation, (3) oxidative damage, and (4) the antioxidant mechanisms of activation on the phase 2 enzyme system.

\section{Materials and methods}

\section{Chemicals}

dl- $\alpha$-LM was purchased from Sigma (Fluka). ( $R$ )- $\alpha$-lipoic acid tris salt (LA)was a gift from KlausWessel (Viatris, Germany) and was used for all experiments. Acrolein was purchased from Sinopharm Chemical Reagent Co., Ltd. (Shanghai, China). All other reagents were purchased from Sigma-Aldrich Chemical Co. (St. Louis, MO, USA).

\section{Cell culture and treatments}

The human ARPE-19 cell line was obtained from Dr. Nancy J. Philip (Thomas Jefferson University, Philadelphia, PA, USA) and cultured in DMEM-F12 medium supplemented with $10 \%$ fetal bovine serum, $2.438 \mathrm{~g} / \mathrm{L}$ sodium bicarbonate, $2 \mathrm{mM}_{\mathrm{L}}$-glutamine, $100 \mathrm{U} / \mathrm{ml}$ penicillin, and $100 \mu \mathrm{g} / \mathrm{ml}$ streptomycin. ARPE-19 cells were used within 10 generations. For all experiments, unless otherwise stated, cells were pretreated with LM or LA for $48 \mathrm{~h}$. The medium was discarded and new medium, with or without $75 \mu \mathrm{M}$ acrolein, was added to the cells for $24 \mathrm{~h}$. Finally, the cells were washed with PBS and collected for assay.

\section{Cell viability and morphology}

Cell viability was measured with a crystal violet staining assay. Cells were cultured in 96-well plates. After treatment, cells were washed twice with PBS, and then fixed with $4 \%$ paraformaldehyde for $30 \mathrm{~min}$. Crystal violet $(0.1 \%)$ was used to stain the cells for $10 \mathrm{~min}$. Excess stain was washed away and crystal violet bound to the cells was dissolved with $10 \%$ acetic acid. Optical densities were measured at $570 \mathrm{~nm}$ with a microplate spectrophotometer (Spectra Max 190; Molecular Devices, Sunnyvale, CA, USA). For cell morphology, cells were 
cultured in 100-mm dishes. Cell morphology was assessed using light microscopy at 10x magnification.

\section{JC-1 assay for mitochondrial membrane potential}

Mitochondrial membrane potential changes in live ARPE-19 cells cultured in 96-well plates were determined using the lipophilic cationic probe 5,5',6,6'-tetrachloro-1, 1',3,3'-tetraethylbenzimidazolylcarbocyanine iodide (JC-1) with a fluorescence spectrometer (Flex Station II 384; Molecular Devices) [18]. The fluorescence ratio (590 to $530 \mathrm{~nm}$ ) was used for quantitative analysis.

\section{MTT assay for qualitative mitochondrial dehydrogenase activity}

The MTT [3-(4,5-dimethyldiazol-2-yl)-2,5-diphenyltetrazolium bromide] reduction assay was used as a qualitative index of mitochondrial dehydrogenase with a microplate spectrophotometer [18].

\section{Mitochondrial complexes I, II, III, IV, and V and pyruvate dehydrogenase activities}

For the activity measurements of mitochondrial enzymes, cells were cultured on 100-mm plates. After various treatments, cells were harvested for enzyme activity measurement. For complexes I and II and pyruvate dehydrogenase (PDH), cells were fragmented by ultrasonication, and the crude homogenates were used to test enzyme activities. For complexes III, IV and V, cell mitochondria were isolated. NADH - CoQ oxidoreductase (complex I) ativity was assayed by Kumar's method [19]. Assays of succinate-CoQ oxidoreductase (complex II), CoQ-cytochrome $c$ reductase (complex III), and cytochrome $c$ oxidase (complex IV) were performed as described [20-22]. Complex V activity was measured as oligomycinsensitive $\mathrm{Mg}^{2+}$-ATPase activity [23]. The PDH assay was carried out according to Hinman's method [24].

\section{Intracellular adenosine 5'-triphosphate (ATP)}

Cells were cultured in six-well plates. After various treatments, cells were lysed by $0.5 \%$ Triton $\mathrm{X}-100$ in $100 \mathrm{mM}$ glycine buffer, $\mathrm{pH}$ 7.4. Intracellular ATP levels were assayed with an ATP bio-luminescence assay kit (Sigma) based on the luciferase-catalyzed oxidation of d-luciferin [25].

\section{Intracellular generation of reactive oxygen species (ROS)}

Intracellular generation of ROS was assayed with the $2^{\prime}, 7^{\prime}$-dichlorofluorescein diacetate (DCFH-DA) method using a fluorescence spectrometer (Flex Station II 384; Molecular Devices) at $488 \mathrm{~nm}$ excitation wavelength and $530 \mathrm{~nm}$ emission wavelength [18].

\section{Intracellular calcium levels}

Intracellular calcium levels were measured with a commercial assay kit (Jiancheng Biochemical, Nanjing, China). In this assay, calcium is reacted with methyl thymol blue to form a blue complex. Optical density was measured at $610 \mathrm{~nm}$ with a microplate reader.

\section{Detection of protein oxidation}

Protein oxidation was determined using the Oxyblot kit (Cell Biolabs, San Diego, CA, USA). Protein carbonyls were labeled by 2,4-dinitrophenylhydrazine and detected by Western blot.

\section{Comet assay for DNA damage}

DNA damage was detected by the comet assay [26]. Cells were imaged using an Olympus BX61 microscope (40× objective) that was linked to an Olympus DP70 microcomputer 
imaging device. Nuclei stained with DAPI were excited with a UV laser $(380 \mathrm{~nm})$. Nuclei with tails were considered to be damaged.

\section{Intracellular GSH levels}

GSH levels were assayed with a commercial kit (Jiancheng Biochemical) based on a thiolspecific reagent, dithionitrobenzoic acid. The adduct was measured spectrophotometrically at $412 \mathrm{~nm}$.

\section{Glutathione S-transferase (GST) activity}

Cells were cultured in six-well plates. After treatment, cells were lysed ultrasonically in 10 $\mathrm{mM}$ sodium phosphate buffer, $\mathrm{pH}$ 6.5. Protein content in the cell lysate was quantified by the BCA method. GST activity was measured in $5 \mathrm{mg}$ protein in the presence of $1 \mathrm{mM} \mathrm{GSH}, 1$ $\mathrm{mM}$ chloro-2,4-dinitrobenzene, $3 \mathrm{mg} / \mathrm{ml} \mathrm{BSA}$ in $10 \mathrm{mM}$ sodium phosphate buffer. The mixture was scanned at $340 \mathrm{~nm}$ for $5 \mathrm{~min}$ at $25^{\circ} \mathrm{C}$ as previously described [27].

\section{Intracellular superoxide dismutase (SOD) activity}

Intracellular SOD activity was assayed with a commercial kit (Jiancheng Biochemical) using a xanthine and xanthine oxidase system to produce superoxide. The superoxide oxidizes hydroxylamine to nitrite to form a carmine-colored reagent and the optical density at $550 \mathrm{~nm}$ was measured with a microplate reader.

\section{Total antioxidant capability}

The total antioxidant capability was assayed with a commercial kit (Jiancheng Biochemical) using a spectrometric method. Ferric ion was reduced by antioxidant reducing agents and the optical density was measured at $520 \mathrm{~nm}$ with a microplate reader.

\section{Nuclear factor-E2-related factor 2 (Nrf2) in total and nuclear proteins}

Cells were grown on 100-mm plates. Total protein and nuclear protein were isolated for Western blot analysis of Nrf2 level. Nrf2 was probed with anti-Nrf2 antibodies (Santa Cruz) at 1:1000 in both total and nuclear proteins. $\beta$-Actin and histone H1 were used as loading controls for total protein and nuclear protein, respectively. Anti- $\beta$-actin antibody (Sigma) was used at 1:10,000 and anti-histone H1 antibody (Upstate) was used at 1:1000.

Chemiluminescence detection was done with an ECL Western blotting detection kit from Amersham Pharmacia [28].

\section{Statistical analysis}

Results are presented as means \pm SEM from at least three independent experiments. Group comparisons were made by one-way ANOVA, followed by determination of significant differences using post hoc comparisons with a Tukey HSD test. A $p$ value $<0.05$ was considered significant.

\section{Results \\ Dose-dependent effects of LM on cell viability and mitochondrial dehydrogenases and membrane potentials}

In order to study any protective effects by LM, AREP-19 cells were pretreated with varying concentrations of $\operatorname{LM}(10$ to $100 \mu \mathrm{M})$ for $48 \mathrm{~h}$ and then treated with $75 \mu \mathrm{M}$ acrolein for $24 \mathrm{~h}$. Cell viability was measured with the crystal violet assay. In Fig. 1A, the solid horizontal line shows the optical density $(\mathrm{OD})$ readings for viable control cells $(\mathrm{OD} \approx 0.28)$. Without pretreatment $(0 \mu \mathrm{MLM})$, acrolein caused a decline in cell viability to about $41.9 \%$ of the control 
$(\mathrm{OD} \approx 0.12)$. In contrast, pretreatment with $\mathrm{LM}$ showed varying improvements to acroleininduced declines in cell viability, with the maximal protective effect in the $40-60 \mu \mathrm{M}$ range of LM pretreatment (Fig. 1A, solid squares and solid line).

Also in Fig. 1A, the broken horizontal line shows the OD readings for control cell mitochondrial dehydrogenase activity (OD $\approx 0.5)$. Acrolein at $75 \mu \mathrm{M}$ for $24 \mathrm{~h}$, without $\mathrm{LM}$ pretreatment, caused a significant decrease in mitochondrial dehydrogenase activity $(\mathrm{OD} \approx 0.3)$. LM pretreatment showed varying, dose-dependent protective effects upon dehydrogenase activities in the 20-100 $\mu \mathrm{M}$ range (Fig. 1A, solid triangles and broken line). Fig. 1B shows similar effects of LM pretreatment for mitochondrial membrane potentials.

For the three measures related to cell viability and mitochondrial functions shown in Fig. 1, maximal protective effects were observed for pretreatment of cells with $40 \mu \mathrm{M} \mathrm{LM}$. Therefore, $40 \mu \mathrm{M} \mathrm{LM}$ was used in the following assays and compared with the same concentration of LA.

\section{Effects on cell viability}

Fig. 2A shows the viability results (OD readings from crystal violet assay) for cells with or without acrolein exposure and with or without $48 \mathrm{~h}$ pretreatment with either $40 \mu \mathrm{M}$ LA or 40 $\mu \mathrm{M}$ LM. Without pretreatment, ARPE-19 cell viability declined about $40 \%$ after treatment with $75 \mu \mathrm{M}$ acrolein. Cells pretreated with $40 \mu \mathrm{M}$ LA or LM, but without acrolein, showed the same viability as the untreated control cells.

For cells exposed to acrolein, pretreatment with $40 \mu \mathrm{M}$ LM showed a statistically significant improvement in cell viability compared to acrolein-exposed cells without pretreatment (Fig. $2 \mathrm{~A})$. However, pretreatment with the same concentration of LA showed no significant improvement (Fig. 2A). Also, based on percentage cell viability, LM pretreatment was more protective than LA $(p<0.05)$.

Fig. 2B shows representative cell morphological images corresponding to the experimental conditions of Fig. 2A (images a-c, no acrolein exposure; d-f, acrolein exposure). Without pretreatment, cells exposed to acrolein (image d) were fewer in number and had significant morphological changes compared to unexposed control cells (image a). LA pretreatment before acrolein exposure (image f) showed some protective effects compared to LA pretreatment without acrolein exposure (image c). However, similar to the results in Fig. 2A, pretreatment with LM before acrolein exposure (image e) showed significant protective effects, with little change in cell numbers or morphological characteristics compared to cells not exposed to acrolein (image b).

\section{Effects on mitochondrial membrane potentials}

LA or LM pretreatments alone had no obvious effects on the membrane potential measured with JC-1 fluorescence (Fig. 3). The fluorescence ratio of ARPE-19 cells decreased to 36.4\% of the control after $75 \mu \mathrm{M}$ acrolein treatment for $24 \mathrm{~h}$. Pretreatment with $40 \mu \mathrm{M}$ LA or LM for $48 \mathrm{~h}$ significantly protected cells from acrolein-induced decreases in membrane potential (Fig. 3). For LA pretreatment, the fluorescence ratio recovered $82.3 \%$ of acrolein-unchallenged levels, and for LM the improvement was $103.5 \%$. LM had about a $20 \%$ greater improvement over LA $(p<0.05)$.

\section{Effects on mitochondrial enzymes}

The MTT assay is a mitochondrial dehydrogenase activity-based test. Pretreatment with 40 $\mu \mathrm{M}$ LA or LM protected cells from the acrolein-induced decrease in cell mitochondrial dehydrogenase (Fig. 4, left). Protection was $72.3 \%$ for LA and $98.9 \%$ for LM. LM was more protective than LA $(p<0.05)$. 
The activities of the mitochondrial electron transport complexes I - V are essential for mitochondrial functions, and PDH is a critical enzyme in the energy metabolism cycle. As shown in Table 1, compared to untreated control cells, acrolein exposure caused decreases of 27.9, 35.2, 19.6, and $48.2 \%$ for complexes I, II, and V and PDH activities, respectively. No significant decreases in activities for complexes III and IV were observed (data not shown).

LA pretreatment was effective in protecting complex I and PDH activities (Table 1). By comparison, LM pretreatment was effective in protecting the activities of all four enzymes whose activities were diminished by acrolein exposure (complexes I, II, and V and PDH). Also, in these four cases, protection by LM was significantly greater than that of LA (Table 1).

\section{Effects on intracellular ATP levels}

Results of assays for ATP levels are shown in Fig. 4 (middle). Acrolein treatment significantly decreased intracellular ATP levels to about $27.0 \%$ of the untreated control level. LM pretreatment significantly inhibited the acrolein-induced decrease in ATP level $(81.1 \%$ of control). LA pretreatment also inhibited the ATP decrease (50.8\% of control), but this level was not statistically different from the group treated with acrolein alone. LM is more effective than LA in inhibiting the acrolein-induced ATP level decrease.

\section{Effects on ROS generation}

Results for intracellular generation of ROS are also shown in Fig. 4 (right). Acrolein treatment caused a significant increase in intracellular generation of ROS, 8.2-fold over that of the control. LM pretreatment inhibited the acrolein-induced ROS generation to normal cell levels. In contrast, LA pretreatment did not show any inhibition of ROS generated by acrolein.

\section{Effects on intracellular calcium levels}

Oxidative stress and mitochondrial dysfunction may either result in or result from an increase in cytoplasmic $\mathrm{Ca}^{2+}$ levels. As shown in Fig. 5, treatment of ARPE-19 cells with $75 \mu \mathrm{M}$ acrolein caused a significant increase in intracellular $\mathrm{Ca}^{2+}$ levels (3.9-fold of control). Similar to the results of oxidant generation shown above, LM pretreatment significantly inhibited the acrolein-induced calcium increase, but LA pretreatment did not show any inhibition.

\section{Effects on protein carbonyls}

Fig. 6A shows representative Western blots for protein carbonyls, and Fig. 6B shows the quantitative results based upon OD scans. Acrolein treatment $(75 \mu \mathrm{M}, 24 \mathrm{~h})$ caused a significant increase in protein carbonyls, 22-fold greater than that of the control. Both LM and LA pretreatments significantly inhibited the acrolein-induced formation of protein carbonyls; the decreased production due to LM pretreatment was significantly greater than that of LA pretreatment $(p<0.01)$.

\section{Effects on DNA damage}

Fig. 7A shows representative images for the comet assay, which reflects DNA fragmentation, and Fig. 7B shows the percentages of cells with DNA damage based on this test. Acrolein treatment $(75 \mu \mathrm{M}, 24 \mathrm{~h})$ caused $89 \%$ nuclear DNA fragmentation. LM pretreatment showed nearly complete protection (only $2 \%$ nuclear DNA fragmentation). This effect was much greater than that observed for LA pretreatment (53\% nuclear DNA fragmentation).

\section{Effects on total antioxidant capacity, intracellular GSH level, and activities of GST and SOD}

Table 2 shows the results from assays for intracellular GSH, SOD, total antioxidant capacity (T-AOC), and GST activity. Acrolein treatment $(75 \mu \mathrm{M}, 24 \mathrm{~h})$ caused significant decreases in 
all of these antioxidant biomarkers. Compared to control levels, these were $26.9 \%$ for GSH level, $68.8 \%$ for SOD activity, $57.2 \%$ for T-AOC, and $13.8 \%$ for GST activity.

Without acrolein exposure, LM or LA pretreatment did not affect these antioxidant biomarkers (Table 2). However, with acrolein exposure, pretreatment with LM significantly protected against all these decreases. LA pretreatment protected against the decreases in GSH, T-AOC, and SOD, but not GST. The protection afforded by LM pretreatment seemed to be greater than that of LA; however, the differences between LM and LA pretreatment were not significant for these parameters (Table 2).

\section{Effects on Nrf2 expression}

Fig. 8 shows Western blot results for Nrf2 expression in total (Figs. 8A and 8B) and nuclear (Figs. 8C and 8D) proteins. Representative blots are shown in Figs. 8A and 8C, and their quantitative results after densitometric scanning are in Figs. 8B and 8D. Acrolein treatment $(75 \mu \mathrm{M}, 24 \mathrm{~h}$ ) caused appreciable losses of Nrf2 expression in both total protein (Figs. 8A and 8B) and nuclear protein (Figs. 8C and 8D). Without acrolein exposure, LM or LA pretreatments did not significantly change Nrf2 expression.

For total protein, both LM and LA pretreatment significantly inhibited the acrolein-induced decrease in Nrf2 expression; LM pretreatment was more effective than LA pretreatment (Figs. $8 \mathrm{~A}$ and $8 \mathrm{~B}$ ). For nuclear protein, LM pretreatment significantly inhibited the acrolein-induced decrease in Nrf2 expression. In contrast, LA pretreatment did not significantly inhibit the acrolein-induced decrease in Nrf2 expression (Figs. 8C and 8D).

\section{Discussion}

Mitochondria are the main generation sites and targets of oxidants [29]. Mitochondrial decay is a key factor in aging and age-related diseases. Increasing evidence shows that aldehydes, including acrolein [30], malondialdehyde [31,32], and 4-hydroxynoneanol [32,33], are reactive oxidants and that these toxins inactivate mitochondrial enzymes and cross-link proteins that are important in the aging process and age-related diseases.

Acrolein, as a major component of cigarette smoke and a by-product of lipid peroxidation, has received special attention as it is a cytotoxic and genotoxic environmental pollutant [6]. Mechanisms of acrolein toxicity have been reported for mitochondrial dysfunction in rat brain [7,23,34], heart [35], and RPE cells [18]. Thus, acrolein-induced toxicity is a useful model for finding antioxidants and protective agents to prevent and to treat diseases associated with increased oxidative damage and mitochondrial dysfunction.

Consistent with previous results [18], as shown here, acrolein treatment induced decreases in cell viability and measures of mitochondrial function, including decreased membrane potentials, activities of complexes I, II, and V and pyruvate dehydrogenase, and total ATP levels. Accompanying the mitochondrial damage, acrolein treatment induced changes in biomarkers of oxidative stress, including oxidant generation, calcium levels, protein oxidation, DNA damage, glutathione levels, expression of the antioxidant response regulator $\mathrm{Nrf2}$, and total antioxidant capacity, and activities of GST and SOD. The acrolein-induced loss of enzyme activity may be attributed to the covalent binding to the enzyme active site to form various adducts, such as acrolein - lysine adducts [36,37].

Both in vitro and in vivo studies have shown that acrolein-induced toxicity is mediated by increased oxidant production and oxidative damage [38], suggesting that acrolein acts not only as a direct oxidant, but also as a generator of oxidants [39]. These newly generated oxidants may cause further loss of enzyme activity. To possibly counteract these effects, we have 
previously shown that LA, a known mitochondrial antioxidant and nutrient, protected RPE cells from acrolein-induced oxidative stress and mitochondrial dysfunction $[9,18]$. However, these protective effects were not absolute, thus making searches for more potent antioxidants a priority.

In this study, we evaluated the protective effects of LM, the neutral amide of LA, which does not occur naturally in animals or plants, using human ARPE-19 as a model. We compared the effects of LM with those of LA for the following measures of acrolein-induced RPE toxicity: (1) cell viability and mitochondrial function, (2) oxidant generation, (3) oxidative damage, and (4) the antioxidant mechanisms of activation on the phase 2 enzyme system.

As shown in Fig. 1A and Fig. 2A, acrolein induced a significant decrease in cell viability measured with the crystal violet assay. LM inhibited the acrolein-induced toxicity, with an optimal effect in the $40-60 \mu \mathrm{M}$ range (Fig. 1A). At $40 \mu \mathrm{M}$ concentration, LM showed greater protective effects than LA for acrolein-induced cellular toxicity (Fig. 2A). These results suggest that LM is an effective protective agent against acrolein-induced ARPE-19 cell toxicity.

One possible mechanism for the cytotoxicity of acrolein may be associated with mitochondrial dysfunction, as we have previously shown that acrolein is a mitochondrial toxin [30]. LM showed dose-dependent protection against acrolein-induced decreases in mitochondrial membrane potentials (measured by JC-1 staining; Fig. 1B), with an optimal dose (40-60 $\mu \mathrm{M})$ similar to that observed for protection of cell viability (Fig. 1A). The protection of mitochondrial membrane potential by LM, similar to its effect on cell viability, was more potent than that of LA at $40 \mu \mathrm{M}$ concentration, as shown by JC-1 fluorescence ratios (Fig. 3).

We used the MTT assay for measuring total mitochondrial dehydrogenase activity, as this assay depends on mitochondrial dehydrogenases for MTT conversion. The results (Fig. 1A and Fig. 4 , left) are similar to those of the JC-1 assay, providing additional evidence for mitochondrial function involvement in acrolein-induced cellular injury. All results from the JC-1 and MTT assays suggest that LM, like LA, is able to protect mitochondria from acrolein-induced injury and that LM is a mitochondrial-protective agent.

Decreased mitochondrial membrane potential leads to dysfunction of mitochondria, such as decreased activities of mitochondrial dehydrogenase and ox-phos enzyme complexes and in ATP synthesis [40]. As with previously discussed results, LM showed significant protective effects against acrolein-induced decreases in the activities of complexes I, II, and V (Table 1); dehydrogenases (Fig. 4, left); and PDH (Table 1) and in the levels of ATP (Fig. 4, middle). In addition, as measured by these mitochondrial parameters, the protective effect of LM was greater than that of LA for the same concentration.

Acrolein is an oxidant that causes damage, such as protein cross-linkage. It can also induce the generation of other reactive oxygen species and cause increases in intracellular calcium [30]. As an antioxidant, LA inhibits oxidative damage by reducing oxidant generation and by increased scavenging of ROS. We compared the effects of LM and LA on the inhibition of acrolein-induced increases in ROS and calcium. As shown in Fig. 4 (right) and Fig. 5, LM showed a greater inhibition of ROS and calcium increases than LA. These results suggest that LM, like LA, is also an effective antioxidant and that this antioxidant activity may account for its protective effects on cell viability and mitochondrial function.

Increased ROS, if not scavenged immediately, will cause oxidative damage to macromolecules, such as proteins/enzymes and DNA, and weaken antioxidant defenses. As LM could inhibit ROS increases in ARPE-19 cells, it should protect proteins/enzymes and DNA from oxidative damage. As expected, LM showed significant protection against acrolein-induced increases in protein oxidation (measured as protein carbonyls; Fig. 6) and oxidative DNA damage (Fig. 7) 
and decreases in total antioxidant capacity and SOD activity (Table 2). All the protective effects of LM were more potent than those of LA at the same concentration $(40 \mu \mathrm{M})$. These results suggest again that LM is a more potent antioxidant than LA.

LA is an inducer of phase 2 enzymes [41]. Nrf2 is a known a key regulator of antioxidant response element-mediated gene expression and inducer of phase 2 enzymes. In previous studies, LA was an effective Nrf2 activator in ARPE-19 cells [18] that enhanced the expression of $\gamma$-glutamylcysteine ligase mRNA in human fetal RPE cells [9]. We examined whether LM could also activate the Keap1/Nrf2 system. As shown in Fig. 8, LM increased Nrf2 expression, and the effect was greater than that of LA at the same concentration. Like LA, LM is a potent inducer of Nrf2 expression.

A consequence of Nrf2 activation is the activation of phase 2 enzymes (GST, heme oxygenase-1, NAD(P)H quinine oxidoreductase-1, $\gamma$-glutamylcysteine ligase) that lead to an increase in antioxidants such as GSH and bilirubin [41,42]. In our study, we measured the activity of one phase 2 enzyme, total GST, and the level of one antioxidant, GSH, as examples of phase 2 system enhancement. LM treatment increased total GST activity and GSH levels, consistent with its ability to stimulate Nrf2 expression. Further studies of other parameters of the Keap1/Nrf2 system are warranted. For example, it is important to study the aldehydespecific isoenzymes of the superfamily GSTs $[43,44]$. A recent study showed that RNAi knockdown of certain GSTs sensitized the nematode to electrophilic stress induced by exposure to 4-hydroxynonenol and that interference with the expression of certain GST genes significantly shortened the life span of the nematode [45].

The positive effects of LA can be attributed to several factors. First, the reduced form of LA, dihydrolipoic acid, is a powerful mitochondrial antioxidant [10,46-48]. It recycles other cellular antioxidants, including $\mathrm{CoQ}$, vitamins $\mathrm{C}$ and $\mathrm{E}$, and glutathione, and chelates iron and copper [10,46-48]. LA readily crosses the blood - brain barrier and is reduced to dihydrolipoic acid by NADH-dependent mitochondrial dihydrolipoamide dehydrogenase [46]. Second, dihydrolipoic acid is an effective transition metal chelator [49]. Third, LA is a redox regulator of proteins such as myoglobin, prolactin, thioredoxin, and transcription factor NF- $\kappa \mathrm{B}[48,50$, 51]. In addition, LA is a cofactor of PDH and $\alpha$-ketoglutarate dehydrogenase.

It has been suggested that increasing enzyme cofactor concentration may be an effective strategy to protect enzymes from oxidant attack or to stimulate defective enzyme activity $[52,53]$. Therefore, administration of LA is beneficial to a number of diseases associated with oxidative stress and mitochondrial dysfunction, such as diabetes, cataracts, HIV activation, neurodegeneration, and radiation injury in animals $[11,18,54,55]$. We clearly showed that LM is more potent than LA at the same concentration for protecting ARPE-19 cells from acroleininduced oxidative stress and mitochondrial dysfunction. All protective effects of LA are attributable to its dithiol group. As LM has the same dithiol group, it is quite possible that it may also be beneficial in treating these diseases.

The reason for the greater protection by LM over LA is not known, but could be attributed to the substitution of $-\mathrm{CONH}_{2}$ for $-\mathrm{COOH}$. The substitution makes $\mathrm{LM}$, compared with LA, relatively more stable than LA. This is attributed to resonance stabilization of CO-N, which is much less acidic at physiological $\mathrm{pH}$ and more lipid soluble, leading to better cellular availability. In addition, the amine group may have other physiological reactions. Further studies are needed for investigating the greater potency of LM compared to LA.

In conclusion, $\mathrm{LM}$, the neutral amide of LM, is more potent than LA in protecting against acrolein-induced oxidative stress and mitochondrial dysfunction in ARPE-19 cells. The strong protective effects of LM against acrolein-induced cytotoxicity suggest that LM may be useful 
for the prevention or treatment of smoking- and age-related degenerative diseases, such as ageassociated macular degeneration.

\section{Abbreviations}

ATP, adenosine 5'-triphosphate

DCFH-DA, 2',7'-dichlorofluorescein diacetate

GST, glutathione S-transferase

JC-1, 5,5',6,6'-tetrachloro-1,1',3,3'-tetraethylbenzimidazolylcarbocyanine iodide

LA, $\alpha$-lipoic acid

LM, lipoamide

MTT, 3-(4,5-dimethyldiazol-2-yl)-2,5-diphenyltetrazolium bromide

Nrf2, nuclear factor-E2-related factor 2

OD, optical density

$\mathrm{PDH}$, pyruvate dehydrogenase

ROS, reactive oxygen species

RPE, retinal pigment epithelial

SOD, superoxide dismutase

T-AOC, total antioxidant capacity.

\section{Acknowledgments}

We are grateful to Dr. Edward Sharman at the University of California at Irvine for his critical and careful reading and editing of the manuscript. This work was supported by the National Eye Institute (NIH Grant EY0160101), Macular Degeneration Research (MDR Grant 2005-038), the Chinese Academy of Sciences (Grant 05PG14104), and the Pujiang Talent Award from the Shanghai Science and Technology Committee, Shanghai, China.

\section{References}

1. Thornton J, Edwards R, Mitchell P, Harrison RA, Buchan I, Kelly SP. Smoking and age-related macular degeneration: a review of association. Eye 2005;19:935-944. [PubMed: 16151432]

2. Khan JC, Thurlby DA, Shahid H, Clayton DG, Yates JR, Bradley M, Moore AT, Bird AC. Smoking and age related macular degeneration: the number of pack years of cigarette smoking is a major determinant of risk for both geographic atrophy and choroidal neovascularisation. Br. J. Ophthalmol 2006;90:75-80. [PubMed: 16361672]

3. Lykkesfeldt J, Christen S, Wallock LM, Chang HH, Jacob RA, Ames BN. Ascorbate is depleted by smoking and repleted by moderate supplementation: a study in male smokers and nonsmokers with matched dietary antioxidant intakes. Am. J. Clin. Nutr 2000;71:530-536. [PubMed: 10648268]

4. O’Neill CA, Halliwell B, van der Vliet A, Davis PA, Packer L, Tritschler H, Strohman WJ, Rieland T, Cross CE, Reznick AZ. Aldehyde-induced protein modifications in human plasma: protection by glutathione and dihydrolipoic acid. J. Lab. Clin. Med 1994;124:359-370. [PubMed: 8083579]

5. Cross CE, O’Neill CA, Reznick AZ, Hu ML, Marcocci L, Packer L, Frei B. Cigarette smoke oxidation of human plasma constituents. Ann. N.Y. Acad. Sci 1993;686:72-89. [PubMed: 8512263]discussion 89-90

6. Esterbauer H, Schaur RJ, Zollner H. Chemistry and biochemistry of 4-hydroxynonenal, malonaldehyde and related aldehydes. Free Radic. Biol. Med 1991;11:81-128. [PubMed: 1937131]

7. Nguyen E, Picklo MJ Sr. Inhibition of succinic semialdehyde dehydrogenase activity by alkenal products of lipid peroxidation. Biochim. Biophys. Acta 2003;1637:107-112. [PubMed: 12527414]

8. Eiserich JP, van der Vliet A, Handelman GJ, Halliwell B, Cross CE. Dietary antioxidants and cigarette smoke-induced biomolecular damage: a complex interaction. Am. J. Clin. Nutr 1995;62:1490S1500S. [PubMed: 7495250]

9. Voloboueva LA, Liu J, Suh JH, Ames BN, Miller SS. R)-Alpha-lipoic acid protects retinal pigment epithelial cells from oxidative damage. Invest. Ophthalmol. Visual Sci 2005;46:4302-4310. [PubMed: 16249512] 
10. Packer L, Roy S, Sen CK. Alpha-lipoic acid: a metabolic antioxidant and potential redox modulator of transcription. Adv. Pharmacol 1997;38:79-101. [PubMed: 8895805]

11. Liu J, Ames BN. Reducing mitochondrial decay with mitochondrial nutrients to delay and treat cognitive dysfunction, Alzheimer's disease, and Parkinson's disease. Nutr. Neurosci 2005;8:67-89. [PubMed: 16053240]

12. Liu Z, Sun L, Zhu L, Jia X, Li X, Jia H, Wang Y, Weber P, Long J, Liu J. Hydroxytyrosol protects retinal pigment epithelial cells from acrolein-induced oxidative stress and mitochondrial dysfunction. J. Neurochem 2007;103:2690-2700.

13. Reed LJ, Koike M, Levitch ME, Leach FR. Studies on the nature and reactions of protein-bound lipoic acid. J. Biol. Chem 1958;232:143-158. [PubMed: 13549405]

14. Sumegi B, Butwell NB, Malloy CR, Sherry AD. LM influences substrate selection in post-ischaemic perfused rat hearts. Biochem. J 1994;297(Pt 1):109-113. [PubMed: 7904156]

15. Szabados E, Fischer GM, Gallyas F Jr, Kispal G, Sumegi B. Enhanced ADP-ribosylation and its diminution by LM after ischemia-reperfusion in perfused rat heart. Free Radic. Biol. Med 1999;27:1103-1113. [PubMed: 10569643]

16. Bisby RH, Parker AW. Antioxidant reactions of dihydrolipoic acid and LM with triplet duroquinone. Biochem. Biophys. Res. Commun 1998;244:263-267. [PubMed: 9514912]

17. Persson HL, Svensson AI, Brunk UT. Alpha-lipoic acid and alpha-LM prevent oxidant-induced lysosomal rupture and apoptosis. Redox Rep 2001;6:327-334. [PubMed: 11778851]

18. Gao J, Zhu ZR, Ding HQ, Qian Z, Zhu L, Ke Y. Vulnerability of neurons with mitochondrial dysfunction to oxidative stress is associated with down-regulation of thioredoxin. Neurochem. Int 2007;50:379-385. [PubMed: 17074421]

19. Kumar MJ, Nicholls DG, Andersen JK. Oxidative alpha-ketoglutarate dehydrogenase inhibition via subtle elevations in monoamine oxidase B levels results in loss of spare respiratory capacity: implications for Parkinson's disease. J. Biol. Chem 2003;278:46432-46439. [PubMed: 12963742]

20. Humphries KM, Szweda LI. Selective inactivation of alpha-ketoglutarate dehydrogenase and pyruvate dehydrogenase: reaction of lipoic acid with 4-hydroxy-2-nonenal. Biochemistry 1998;37:15835-15841. [PubMed: 9843389]

21. Picklo MJ, Amarnath V, McIntyre JO, Graham DG, Montine TJ. 4-Hydroxy-2(E)-nonenal inhibits CNS mitochondrial respiration at multiple sites. J. Neurochem 1999;72:1617-1624. [PubMed: 10098869]

22. Calon F, Lim GP, Yang F, Morihara T, Teter B, Ubeda O, Rostaing P, Triller A, Salem N Jr, Ashe $\mathrm{KH}$, Frautschy SA, Cole GM. Docosahexaenoic acid protects from dendritic pathology in an Alzheimer's disease mouse model. Neuron 2004;43:633-645. [PubMed: 15339646]

23. Picklo MJ, Montine TJ. Acrolein inhibits respiration in isolated brain mitochondria. Biochim. Biophys. Acta 2001;1535:145-152. [PubMed: 11342003]

24. Hinman LM, Blass JP. An NADH-linked spectrophotometric assay for pyruvate dehydrogenase complex in crude tissue homogenates. J. Biol. Chem 1981;256:6583-6586. [PubMed: 7240230]

25. Patane G, Anello M, Piro S, Vigneri R, Purrello F, Rabuazzo AM. Role of ATP production and uncoupling protein-2 in the insulin secretory defect induced by chronic exposure to high glucose or free fatty acids and effects of peroxisome proliferator-activated receptor-gamma inhibition. Diabetes 2002;51:2749-2756. [PubMed: 12196468]

26. Kwong LK, Mockett RJ, Bayne AC, Orr WC, Sohal RS. Decreased mitochondrial hydrogen peroxide release in transgenic Drosophila melanogaster expressing intramitochondrial catalase. Arch. Biochem. Biophys 2000;383:303-308. [PubMed: 11185567]

27. Pabst MJ, Habig WH, Jakoby WB. Glutathione S-transferase A: a novel kinetic mechanism in which the major reaction pathway depends on substrate concentration. J. Biol. Chem 1974;249:7140-7147. [PubMed: 4436301]

28. Smith AR, Shenvi SV, Widlansky M, Suh JH, Hagen TM. Lipoic acid as a potential therapy for chronic diseases associated with oxidative stress. Curr. Med. Chem 2004;11:1135-1146. [PubMed: 15134511]

29. Shigenaga MK, Hagen TM, Ames BN. Oxidative damage and mitochondrial decay in aging. Proc. Natl. Acad. Sci. U. S. A 1994;91:10771-10778. [PubMed: 7971961] 
30. Sun L, Luo C, Long J, Wei D, Liu J. Acrolein is a mitochondrial toxin: effects on respiratory function and enzyme activities in isolated rat liver mitochondria. Mitochondrion 2006;6:136-142. [PubMed: 16725382]

31. Long J, Wang X, Gao H, Liu Z, Liu C, Miao M, Liu J. Malonaldehyde acts as a mitochondrial toxin: inhibitory effects on respiratory function and enzyme activities in isolated rat liver mitochondria. Life Sci 2006;79:1466-1472. [PubMed: 16737718]

32. Liu J, Killilea DW, Ames BN. Age-associated mitochondrial oxidative decay: improvement of carnitine acetyltransferase substrate-binding affinity and activity in brain by feeding old rats acetyl1-carnitine and/or R-alpha-lipoic acid. Proc. Natl. Acad. Sci. U. S. A 2002;99:1876-1881. [PubMed: $11854488]$

33. Humphries KM, Yoo Y, Szweda LI. Inhibition of NADH-linked mitochondrial respiration by 4hydroxy-2-nonenal. Biochemistry 1998;37:552-557. [PubMed: 9425076]

34. Luo J, Shi R. Acrolein induces oxidative stress in brain mitochondria. Neurochem. Int 2005;46:243252. [PubMed: 15670641]

35. Biagini RE, Toraason MA, Lynch DW, Winston GW. Inhibition of rat heart mitochondrial electron transport in vitro: implications for the cardiotoxic action of allylamine or its primary metabolite, acrolein. Toxicology 1990;62:95-106. [PubMed: 2343460]

36. Uchida K, Kanematsu M, Morimitsu Y, Osawa T, Noguchi N, Niki E. Acrolein is a product of lipid peroxidation reaction: formation of free acrolein and its conjugate with lysine residues in oxidized low density lipoproteins. J. Biol. Chem 1998;273:16058-16066. [PubMed: 9632657]

37. Uchida K, Kanematsu M, Sakai K, Matsuda T, Hattori N, Mizuno Y, Suzuki D, Miyata T, Noguchi N, Niki E, Osawa T. Protein-bound acrolein: potentialmarkers for oxidative stress. Proc. Natl. Acad. Sci. U. S. A 1998;95:4882-4887. [PubMed: 9560197]

38. Collins AR. The comet assay for DNA damage and repair: principles, applications, and limitations. Mol. Biotechnol 2004;26:249-261. [PubMed: 15004294]

39. Adams JD Jr, Klaidman LK. Acrolein-induced oxygen radical formation. Free Radic. Biol. Med 1993;15:187-193. [PubMed: 8397144]

40. Wallace DC. A mitochondrial paradigm of metabolic and degenerative diseases, aging, and cancer: a dawn for evolutionary medicine. Annu. Rev. Genet 2005;39:359-407. [PubMed: 16285865]

41. Liu J. The effects and mechanisms of mitochondrial nutrient alpha-lipoic acid on improving ageassociated mitochondrial and cognitive dysfunction: an overview. Neurochem. Res 2008;33:194203. [PubMed: 17605107]

42. Satoh T, Okamoto SI, Cui J, Watanabe Y, Furuta K, Suzuki M, Tohyama K, Lipton SA. Activation of the Keap1/Nrf2 pathway for neuroprotection by electrophilic phase II inducers. Proc. Natl. Acad. Sci. U. S. A 2006;103:768-773. [PubMed: 16407140]

43. Laisney V, Nguyen Van C, Gross MS, Frezal J. Human genes for glutathione S-transferases. Hum. Genet 1984;68:221-227. [PubMed: 6500576]

44. Vorachek WR, Pearson WR, Rule GS. Cloning, expression, and characterization of a class-Mu glutathione transferase from human muscle, the product of the GST4 locus. Proc. Natl. Acad. Sci.U. S. A 1991;88:4443-4447. [PubMed: 2034681]

45. Ayyadevara S, Dandapat A, Singh SP, Siegel ER, Shmookler Reis RJ, Zimniak L, Zimniak P. Life span and stress resistance of Caenorhabditis elegans are differentially affected by glutathione transferases metabolizing 4-hydroxynon-2-enal. Mech. Ageing Dev 2007;128:196-205. [PubMed: 17157356]

46. Moini H, Packer L, Saris NE. Antioxidant and prooxidant activities of alpha-lipoic acid and dihydrolipoic acid. Toxicol. Appl. Pharmacol 2002;182:84-90. [PubMed: 12127266]

47. Packer L, Tritschler HJ, Wessel K. Neuroprotection by the metabolic antioxidant alpha-lipoic acid. Free Radic. Biol. Med 1997;22:359-378. [PubMed: 8958163]

48. Packer L, Witt EH, Tritschler HJ. a-Lipoic acid as a biological antioxiant. Free Radic. Biol. Med 1995;19:227-250. [PubMed: 7649494]

49. Ou P, Tritschler HJ, Wolff SP. hioctic (lipoic) acid: a therapeutic metal-chelating antioxidant? Biochem. Pharmacol 1995;50:123-126. [PubMed: 7605337]

50. Bustamante J, Lodge JK, Marcocci L, Tritschler HJ, Packer L, Rihn BH. Alpha-lipoic acid in liver metabolism and disease. Free Radic. Biol. Med 1998;24:1023-1039. [PubMed: 9607614] 
51. Fuchs, J.; Packer, L.; Zimmer, G. Lipoic acid in health and disease. New York: Dekker; 1997.

52. Ames BN, Elson-Schwab I, Silver EA. High-dose vitamin therapy stimulates variant enzymes with decreased coenzyme binding affinity (increased $\mathrm{K}(\mathrm{m})$ ): relevance to genetic disease and polymorphisms. Am. J. Clin. Nutr 2002;75:616-658. [PubMed: 11916749]

53. Ames, BN.; Liu, J.; Suh, JH. Enzymes lose binding affinity (increase Km) for coenzymes and substrates with age: a strategy for remediation. In: Kaput, J.; Rodriguez, RL., editors. Nutritional genomics: discovering the path to personalized nutrition. Hoboken, NJ: Wiley; 2006. p. 277-291.

54. Packer L, Kraemer K, Rimbach G. Molecular aspects of lipoic acid in the prevention of diabetes complications. Nutrition 2001;17:888-895. [PubMed: 11684397]

55. Holmquist L, Stuchbury G, Berbaum K, Muscat S, Young S, Hager K, Engel J, Munch G. Lipoic acid as a novel treatment for Alzheimer's disease and related dementias. Pharmacol. Ther 2007;113:154-164. [PubMed: 16989905] 

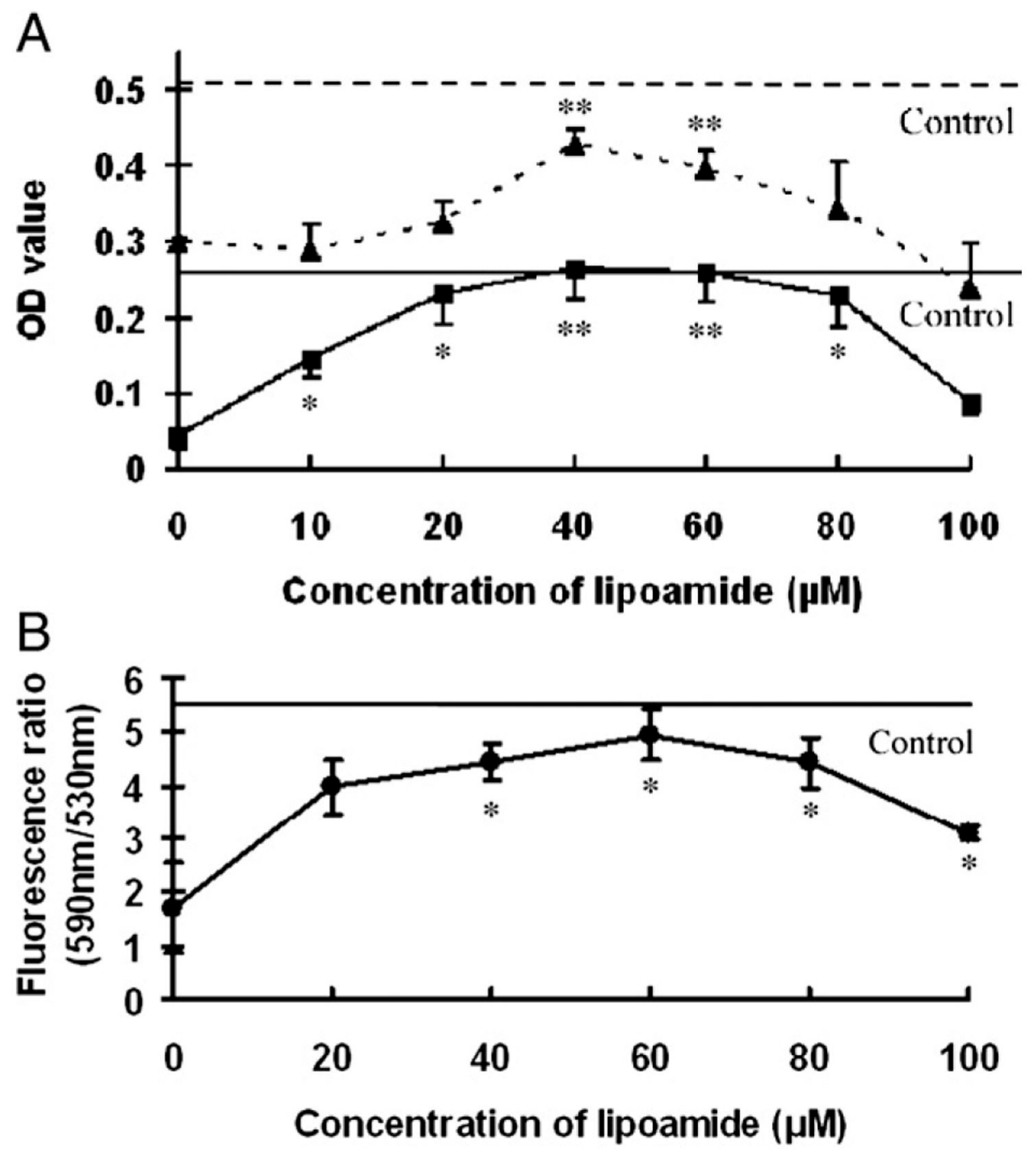

Fig. 1.

Effects of LM on acrolein-induced damage to cell viability, mitochondrial dehydrogenase activity, and mitochondrial membrane potential. ARPE-19 cells were pretreated with the indicated concentrations of LM before acrolein exposure. (A) Cell viability: solid horizontal line is the optical density (OD) reading for untreated control cells stained with crystal violet. Filled squares and solid line are OD readings for cells pretreated with LM before acrolein exposure. Mitochondrial dehydrogenase activity: broken horizontal line is the OD reading for untreated control cells. Filled triangles and broken line are OD readings for cells pretreated with LM before acrolein exposure. (B) Mitochondrial membrane potential. Solid horizontal line is the $590 \mathrm{~nm} / 530 \mathrm{~nm}$ fluorescence ratio for untreated control cells. Filled circles and solid line are the ratios for cells pretreated with LM before acrolein exposure. Values are means \pm SEM for three independent experiments in eight wells each, except for $100 \mu \mathrm{M}(\mathrm{n}=2)$. ${ }^{*} p<0.05$ and ${ }^{* *} p<0.01$ vs $0 \mu \mathrm{M}$ LM pretreatment. 

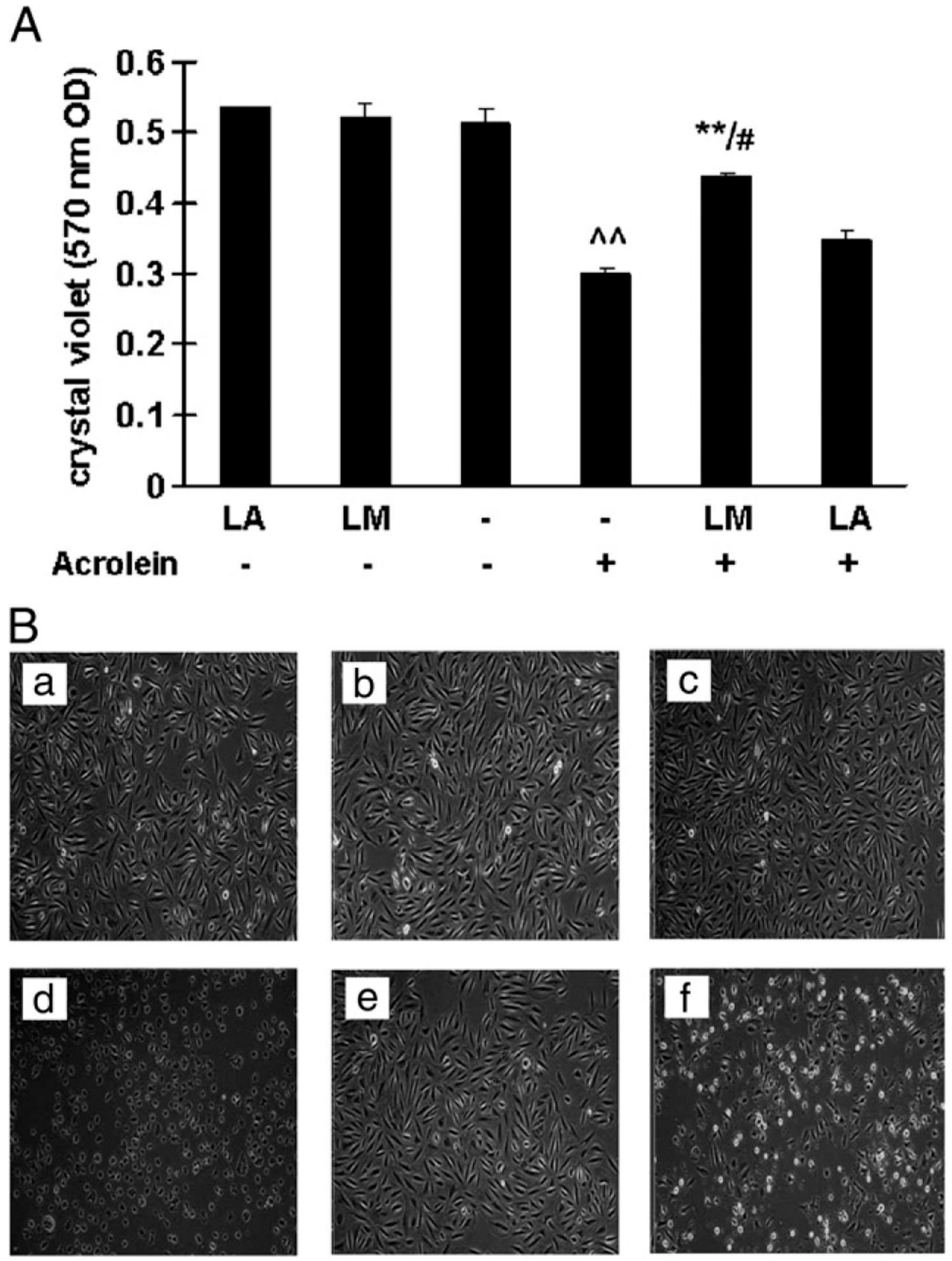

Fig. 2.

Effects of LM and LA on acrolein-induced decreases in cell viability. (A) Cell viability was assayed with crystal violet. Values are means \pm SEM from three independent experiments, three wells each. ${ }^{\wedge} p p<0.01$ vs control; $* * p<0.01$ vs acrolein; $\# p<0.05$ vs LA + acrolein. (B)

Representative images of cell morphology. (a) Control; (b) LM alone; (c) LA alone; (d) acrolein only; (e) LM + acrolein; (f) LA + acrolein. Images from light microscopy at 10× original magnification. 


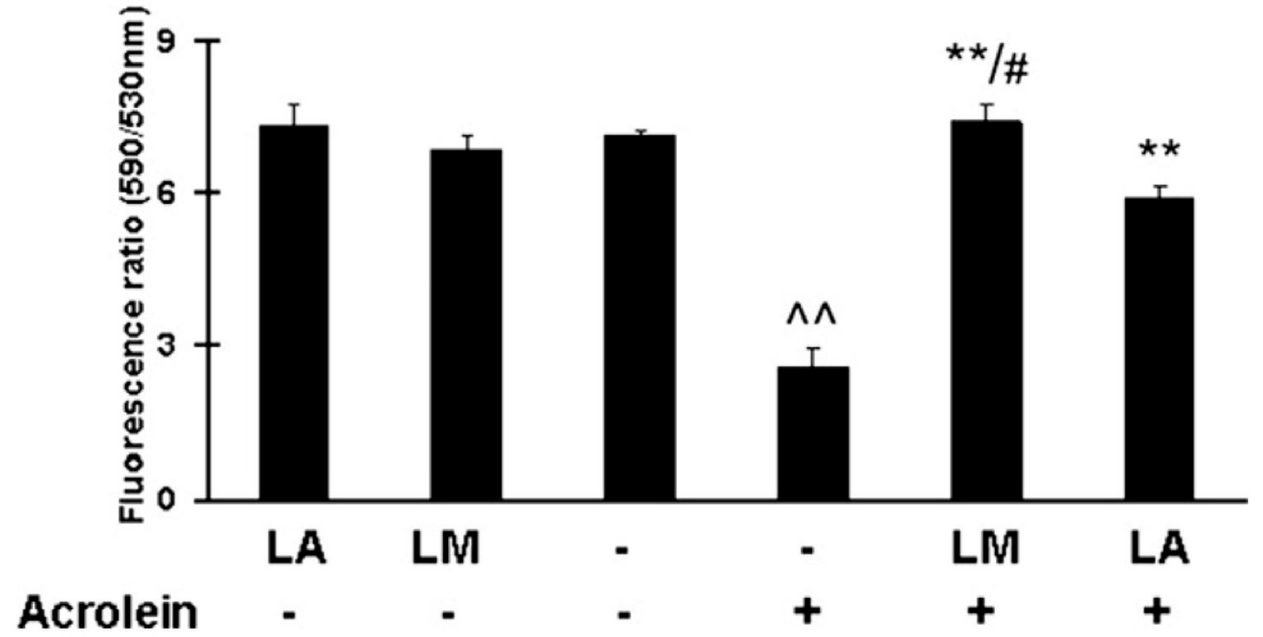

Fig. 3.

Effects of LM and LA on acrolein-induced decreases in mitochondrial membrane potential. Data are red/green $(590 \mathrm{~nm} / 530 \mathrm{~nm})$ fluorescence ratios. Values are means \pm SEM from three independent experiments, in eight wells each. ${ }^{\wedge} p<0.01 \mathrm{vs}$ control; ${ }^{* *} p<0.01 \mathrm{vs}$ acrolein; $\# p<0.05$ vs LA + acrolein. 


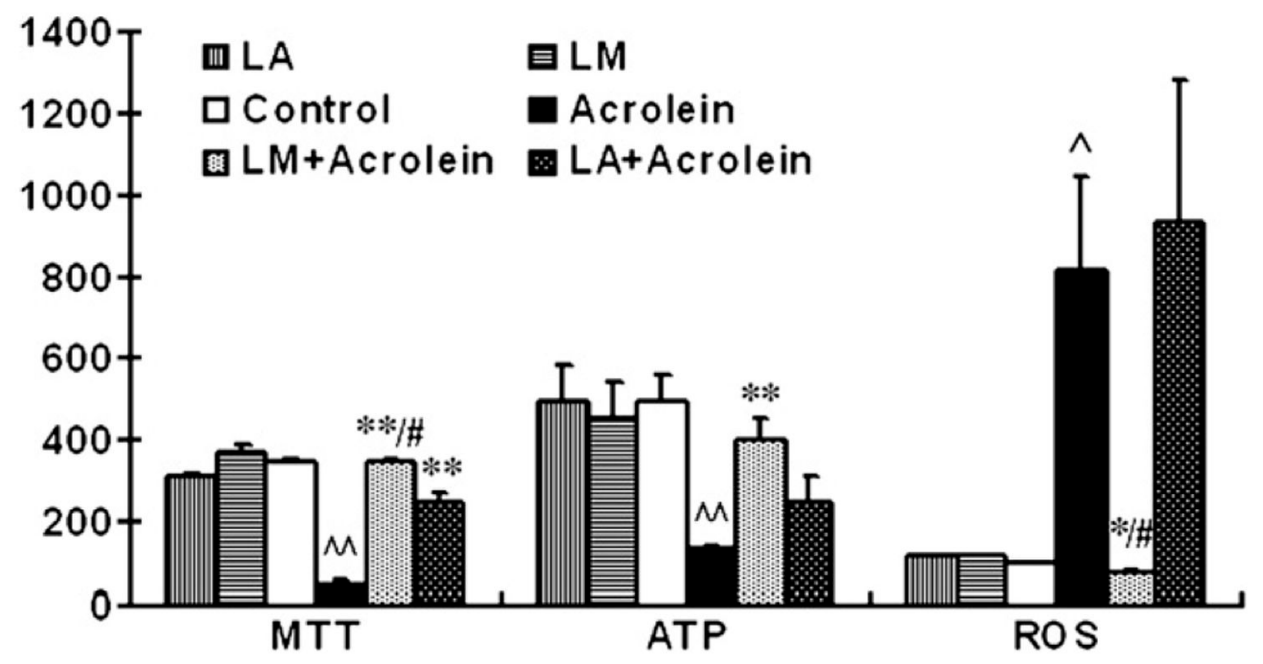

Fig. 4.

Effects of LM and LA on acrolein-induced changes in mitochondrial dehydrogenases, intracellular ATP levels, and reactive oxygen species level. (Left) Mitochondrial dehydrogenases assayed with MTT assay; expressed as milli-OD. Results are means \pm SEM of three independent experiments, in eight wells each. (Middle) Intracellular ATP levels expressed as luminescence value per milligram of protein. Values are means $\pm \operatorname{SEM}(n=4)$. (Right) ROS generation tested with DCF-DA staining expressed as ratio relative to controls. Values are means \pm SEM of five independent experiments. ${ }^{\wedge} p<0.05,{ }^{\wedge} p<<0.01 \mathrm{vs} \mathrm{control;}$ ${ }^{*} p<0.05, * * p<0.01$ vs acrolein; $\# p<0.05$ vs LA + acrolein. 


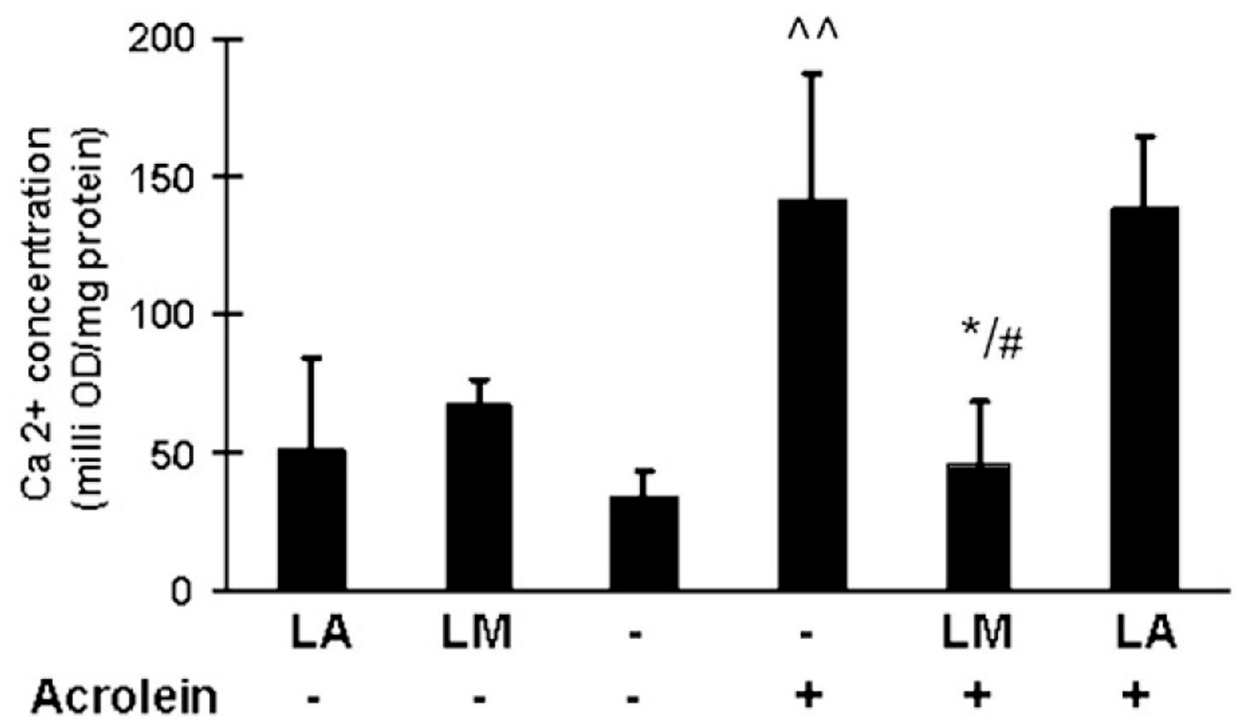

Fig. 5.

Effects of LM and LA on acrolein-induced increases in intracellular calcium levels. Intracellular calcium measured by spectrophotometry method; results are milli-OD/mg protein. Values are means $\pm \operatorname{SEM}(n=3) .{ }^{\wedge} p<<0.01$ vs control; ${ }^{*} p<0.05$ vs acrolein; $\# p<0.05$ vs LA + acrolein. 
A
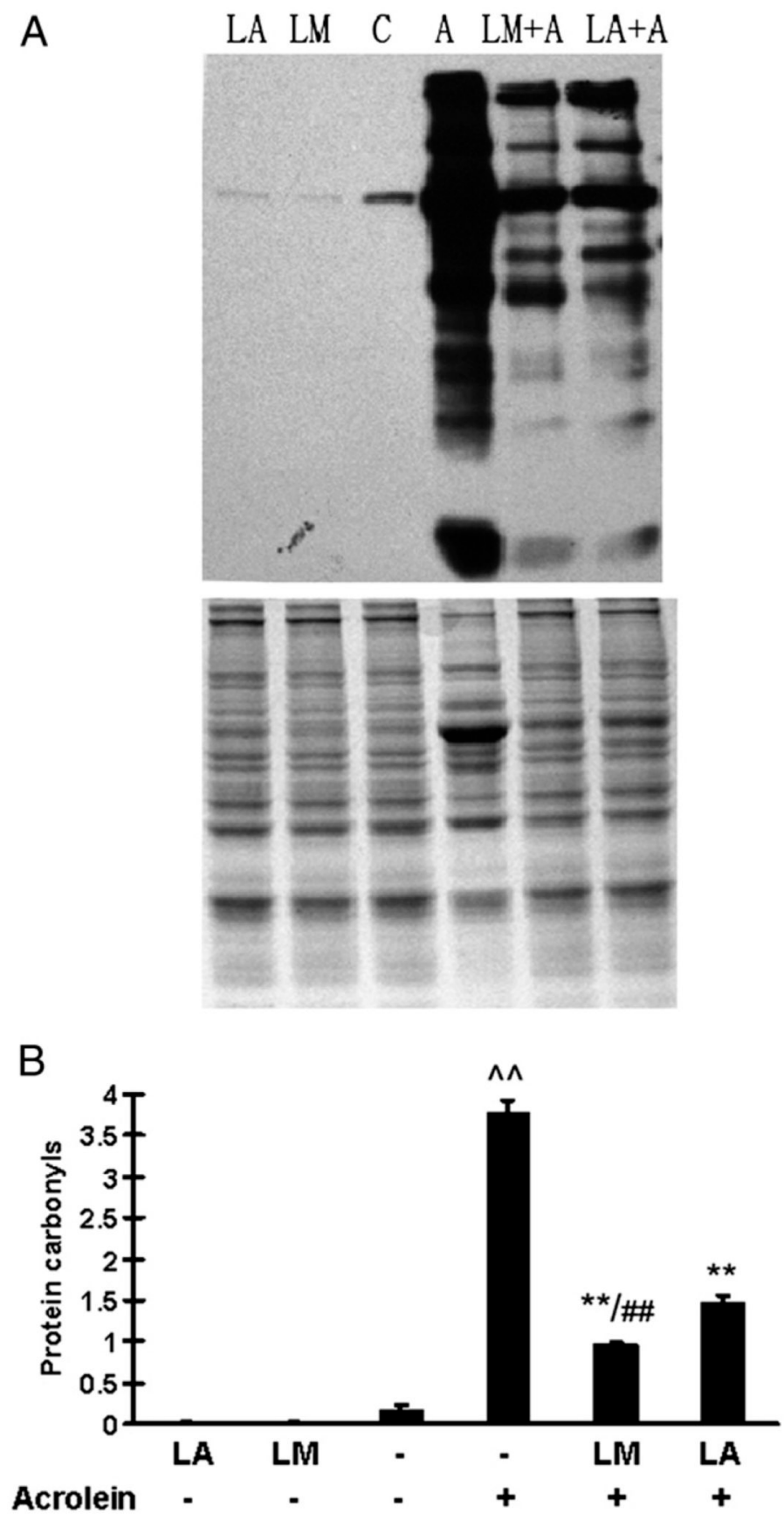

Fig. 6.

Effects of LM and LA on acrolein-induced increases in protein carbonyls. (A) Western blots of protein carbonyls (top) and total protein as a loading control (bottom) stained with Coomassie blue. (B) Quantitative optical density results. Values are means \pm SEM of three independent experiments. ${ }^{\wedge \wedge} p<0.01$ vs control; ${ }^{* *} p<0.01$ vs acrolein; \#\#p<0.01 vs LA + acrolein. 

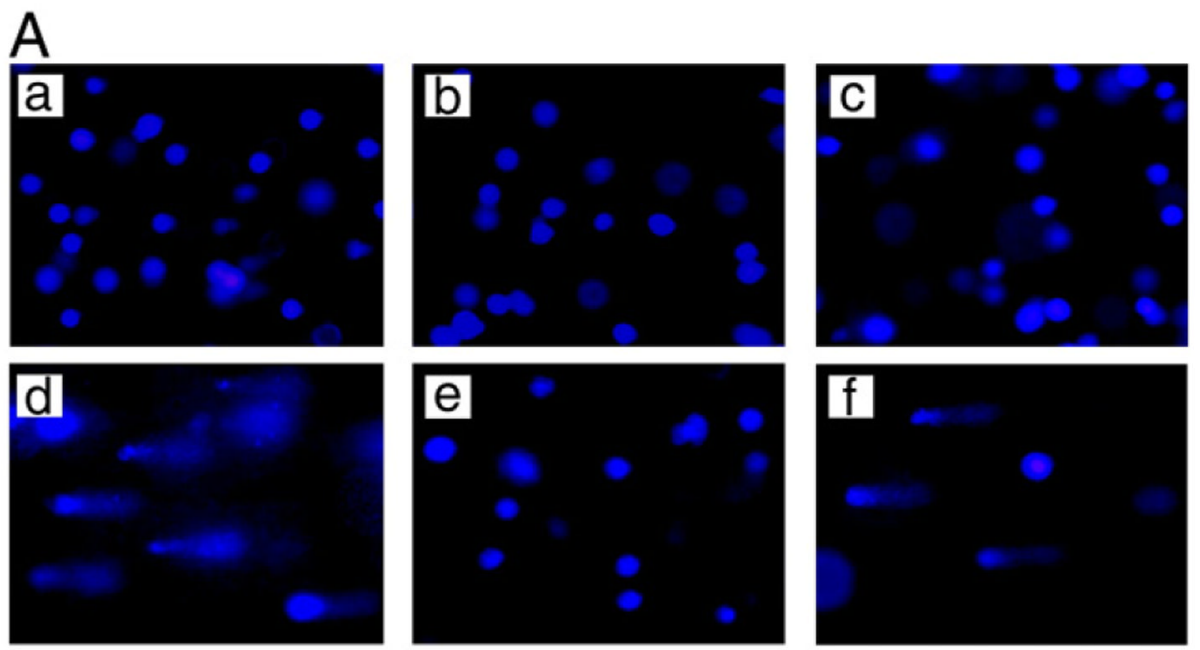

$\mathrm{B}$

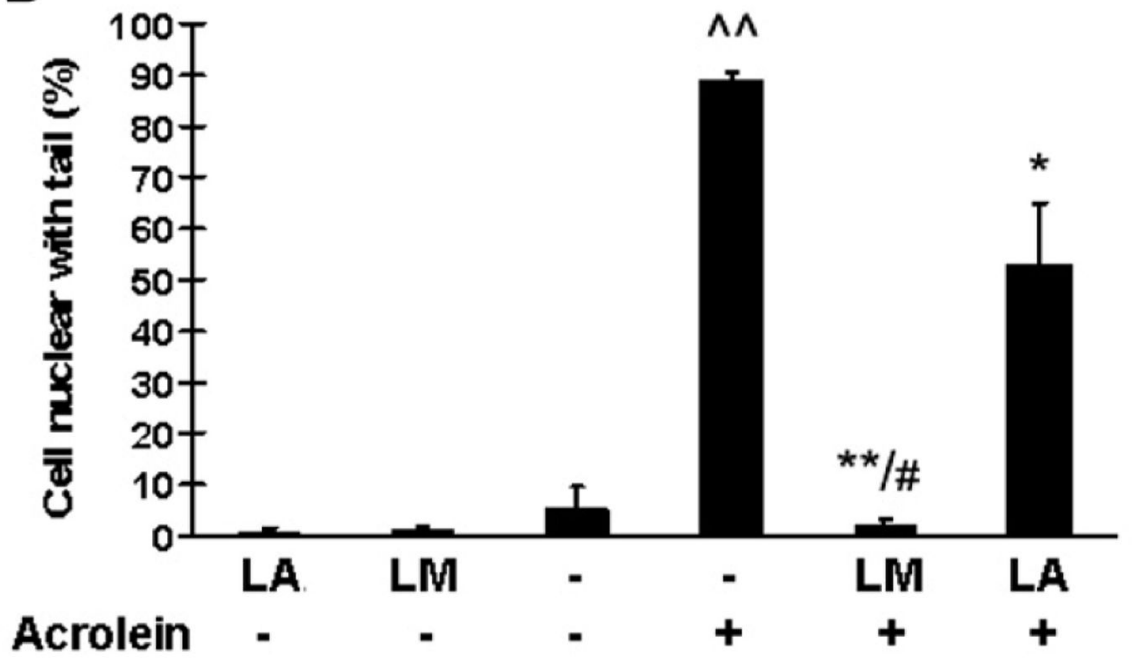

Fig. 7.

Effects of LM and LA on acrolein-induced increases in DNA damage. (A) Representative images of comet assay results. (B) Percentage nuclear fragmentation from three independent experiments. More than 100 cells were analyzed in each experimental group. Values are means \pm SEM. ${ }^{\wedge} p<<0.01$ vs control; ${ }^{*} p<0.05$ and ${ }^{* *} p<0.01$ vs acrolein; $\# p<0.01$ vs LA + acrolein. 

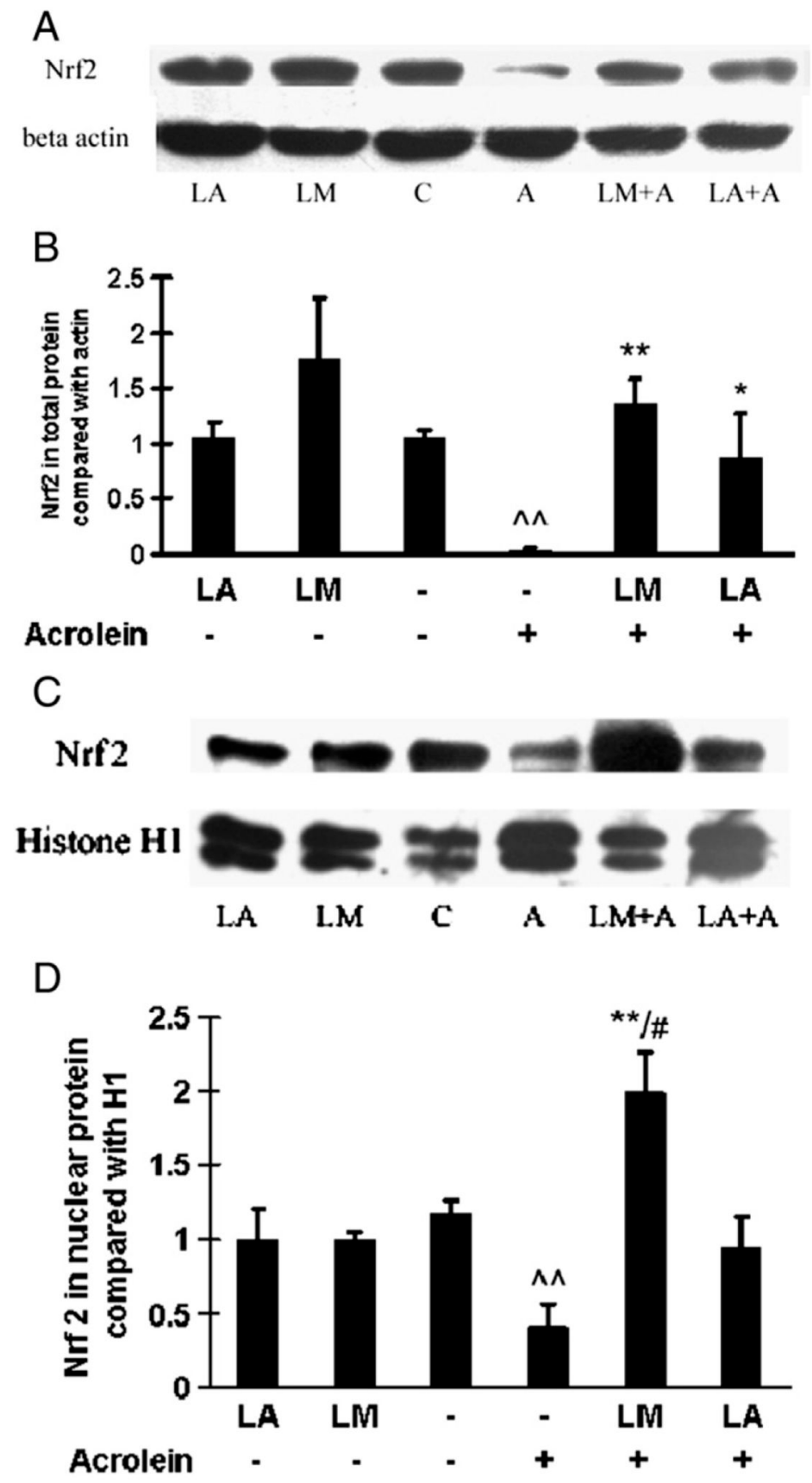

Fig. 8.

Effects of LM and LA on Nrf2 expression in total and nuclear protein. Representative Western blots for $\mathrm{Nr} 2 \mathrm{f}$ expression in (A) total protein and (C) nuclear protein. Optical density was analyzed by Quantity One software and normalized with (B) $\beta$-actin for total protein or (D) histone $\mathrm{H} 1$ for nuclear protein. Values are means \pm SEM of four independent Western blots. ${ }^{\wedge} p<<0.01$ vs control; ${ }^{*} p<0.05$ and ${ }^{* *} p<0.01$ vs acrolein; $\# p<0.05$ vs LA + acrolein. 


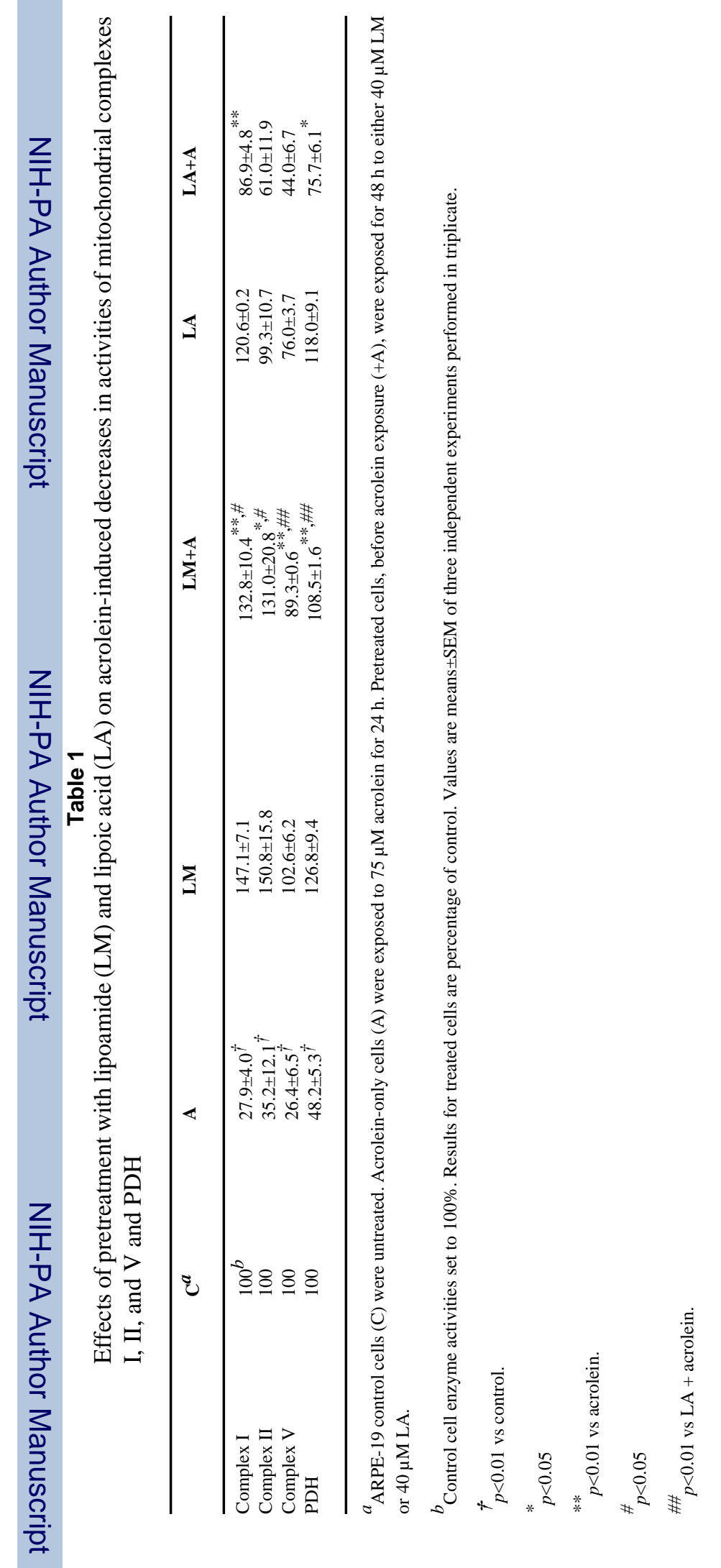




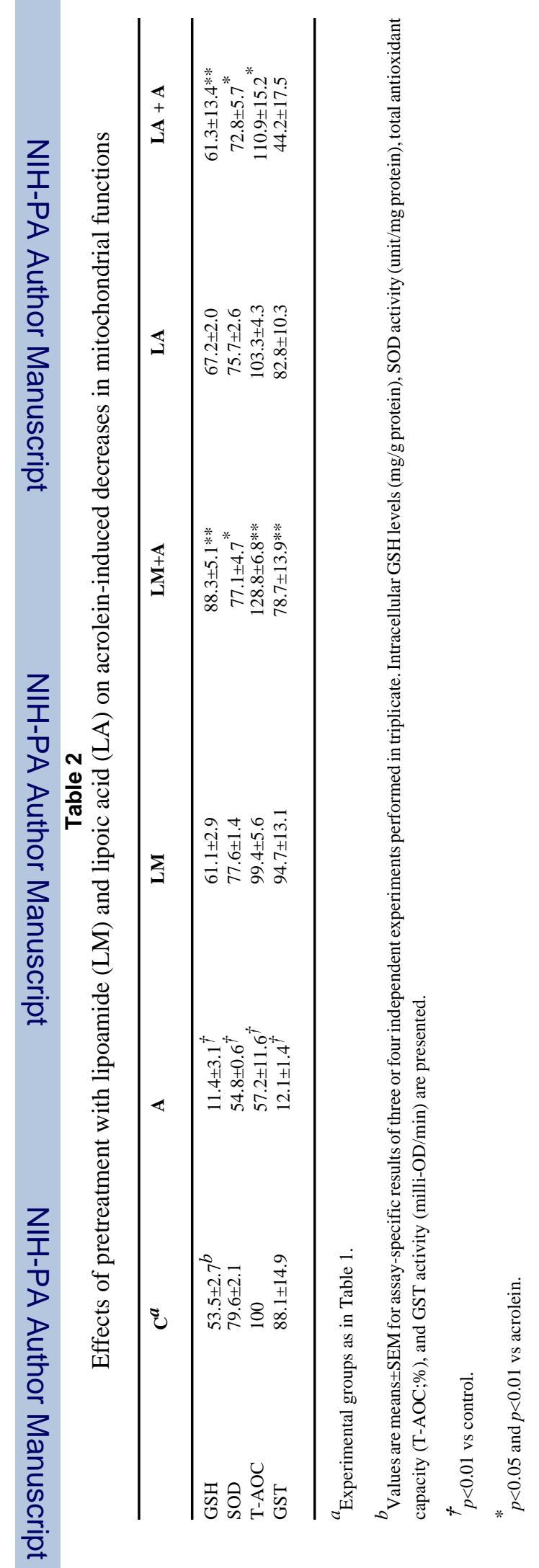

